\title{
The new Back to Basics section: emerging concepts in basic and translational medicine
}

\author{
Melanie Königshoff ${ }^{1,2}$
}

Affiliations: ${ }^{1}$ Comprehensive Pneumology Center, University Hospital, Ludwig-Maximilians University, Helmholtz Zentrum München, Munich, Germany. ${ }^{2}$ Member of the German Center for Lung Research (DZL).

Correspondence: Melanie Königshoff, Comprehensive Pneumology Center, Helmholtz Zentrum München, University Hospital, Ludwig-Maximilians University, Max-Lebsche-Platz 31, München 81377, Germany.

E-mail: melanie.koenigshoffahelmholtz-muenchen.de

0

@ERSpublications

The \#ERJ launches a new Back to Basics section discussing novel concepts in basic science and translational medicine http://ow.ly/y8SL5

We can't solve problems by using the same kind of thinking we used when we created them.

Albert Einstein

The European Respiratory Journal (ERJ), the flagship publication of the European Respiratory Society (ERS), is launching a new section on novel concepts in physiology, immunology, biology and translational medicine $[1,2]$. Within this Back to Basics section, we aim to present cutting edge knowledge and emerging ideas on topics relevant to respiratory medicine. Basic scientific findings represent the essential foundation for advances in clinical medicine, and a close and continuous exchange between basic and clinical scientists is key to improved diagnosis and therapy for our patients. This new section underlines the importance of discussing basic scientific findings and their potential for translation into clinical practice, which will ultimately lead to better patient care.

The new Back to Basics section will comprise several formats that comprehensively highlight the different aspects and multifaceted implications of basic science for clinical medicine. These articles will be published back to back with the best original work in respiratory science and medicine in the ERJ, and will include conference reports and summaries, translational reviews, and stand-alone editorials.

"Science should thread through all the society's activities" [3]: one of the major objectives of the ERS is to foster respiratory science and scientific exchange by promoting basic, epidemiological and clinical research in respiratory medicine. Several ERS activities aim to fulfil these objectives, including the Lung Science Conference, in which the very best of international lung science research is presented and discussed between young doctoral and postdoctoral scientists with established investigators. Moreover, ERS research seminars on hot topics bring together researchers from within and outside lung medicine, and are meant to be think tanks on how to develop a specific research field for the future. The ERJ provided conference and seminar reports in the past, and will continue to do so on a regular basis in order to disseminate and multiply major findings and discussions arising from these activities [4-6].

One of the main pillars of the new Back to Basics section will be translational review articles on basic science topics, which will cover exciting scientific advances in all fields of respiratory medicine and thoracic surgery. Recent developments and novel concepts will be put into context and new strategies, but also limitations and possibly translational gaps, will be outlined for a better understanding of prevention, diagnosis or

Received: June 132014 | Accepted: June 132014

Conflict of interest: None declared.

Copyright @ERS 2014 
treatment of lung disease. In this issue of the ERJ, VALLATH et al. [7] outline the role of the epidermal growth factor receptor signalling pathway in chronic lung disease and discuss its potential for therapeutic application. The discovery of the cystic fibrosis transmembrane conductance regulator (CFTR) gene 25 years ago represents another outstanding example of how a field progressed and improved in the light of excellent complementary basic and clinical science. Upon the initial identification of CFTR, numerous studies addressing its molecular and cell biological consequences and clinical implications have been initiated, and have led to major insights into the pathogenesis and therapy of cystic fibrosis today. One of the first Back to Basics translational review articles highlights these major advances in our understanding of cystic fibrosis development and progression as well as the therapeutic consequences thereof [8].

Moreover, we encourage sharp, high-quality editorials that particularly address the most recently published basic science breakthroughs (also original article(s) published elsewhere) and inform the ERJ readership about highly important research findings. We kick off this in the current issue, with an editorial on epithelial stem cells and airway regeneration [9].

Altogether, we aim to stimulate active discussion and correspondence among our readership. Diverse opinions and controversy drive innovation and progress within all areas of society, in particular in science and medicine. As a special feature, the Back to Basics section will represent a forum to highlight novel and/ or controversial ideas and hypotheses, and inspire our readers to think outside the box.

The new Back to Basics section represents an excellent addition to the original work on respiratory science and medicine in the ERJ, as well as to the newly planned State of the Art section presenting high-level clinical information.

We hope you will enjoy this new section of the ERJ and warmly invite you to get actively engaged in and contribute to this new format, and thus facilitate scientific exchange and progress among junior and established healthcare professionals and scientists in respiratory medicine.

\section{References}

Humbert M. The ambition of the European Respiratory Journal. Eur Respir J 2013; 41: 1-2.

Humbert M. The ambition of the European Respiratory Journal: chapter 2. Eur Respir J 2014; 43: 1-2.

Migliori GB, Rabe KF, Bel E, et al. The European Respiratory Society plans its future: the 2013-2018 strategic plan. Eur Respir J 2014; 43: 927-932.

4 Hofmann HJ. Basic mechanisms of lung inflammation: executive summary of the first Lung Science Meeting of the European Respiratory Society at Taormina, Italy in 2003. Eur Respir J 2003; 22: Suppl. 44, 1s-3s.

5 Königshoff M, Saglani S, Marsland BJ, et al. Rebuilding a diseased lung: repair and regeneration. Eur Respir J 2013; 41: 497-499.

6 Meiners S, Greene C. Protein quality control in lung disease: it's all about cloud-networking. Eur Respir J 2014 [In press DOI: $10.1183 / 09031936.00105214]$.

7 Vallath S, Hynds RE, Succony L, et al. Targeting EGFR signalling in chronic lung disease: therapeutic challenges and opportunities. Eur Respir J 2014; 44: 513-522.

Mall MA, Hartl D. CFTR: cystic fibrosis and beyond. Eur Respir J 2014 [In press DOI: 10.1183/09031936.00228013].

9 Rawlins EL, Giangreco A. The best laid schemes of airway repair. Eur Respir J 2014; 44: 299-301. 